\title{
Development of a high throughput screening assay for inhibitors of hedgehog-heparin interactions
}

This article was published in the following Dove Press journal:

International Journal of High Throughput Screening

10 May 2010

Number of times this article has been viewed

\section{Laura R Daye \\ Willietta Gibson \\ Kevin P Williams}

Department of Pharmaceutical Sciences, Biomanufacturing Research Institute and Technology Enterprise, North Carolina Central University, Durham, NC, USA
Correspondence: Kevin PWilliams Biomanufacturing Research Institute and Technology Enterprise, North Carolina Central University, I80I Fayetteville Street, Durham, NC 27707, USA

Tel +19195307726

Fax + I 9195306600

Email kpwilliams@nccu.edu

\begin{abstract}
The activity of hedgehog ligand is mediated in part by interactions with heparin and heparan sulfate proteoglycans. In order to identify inhibitors that block the interaction of hedgehog with heparin, we have developed a simple and robust high throughput assay based on fluorescence polarization. This assay utilizing fluorescein-labeled heparin binding to sonic hedgehog N-terminal domain ( $\mathrm{ShhN}$ ) protein was developed and optimized in a 384-well format. ShhN bound to fluorescein-labeled heparin with high affinity $\left(K_{D}=99 \mathrm{nM}\right)$ and the interaction was shown to be stable over time and tolerant to dimethyl sulfoxide (DMSO). A panel of unlabeled heparins of varying molecular weights was tested in the assay, with lower $\mathrm{IC}_{50}$ values correlating with heparins of increasing size. The assay was automated into two simple steps, and validation with whole DMSO plates yielded a Z' factor of 0.56 , indicating a robust assay for high throughput screening. We predict that this assay will be suitable for identifying chemical probes of hedgehog ligand-heparin interactions. Further, compounds that disrupt the ShhN interaction with heparin and/or heparan sulfate proteoglycans may be considered as potential therapeutics for those cancers driven by Hh ligand overexpression.
\end{abstract}

Keywords: hedgehog, heparin, fluorescence polarization, high throughput screening

\section{Introduction}

The hedgehog (Hh) family of secreted proteins (sonic [Shh], indian [Ihh], and desert [Dhh]) play fundamental roles in embryonic development and control the development of many tissues. ${ }^{1}$ Many of the downstream signaling events in Hh signaling have been elucidated from genetic and biochemical studies. ${ }^{2}$ All $\mathrm{Hh}$ ligands seem to bind to the same receptors and regulate the same signaling pathway, ${ }^{3}$ but have differing functional responses. ${ }^{4}$ The active processed $\mathrm{N}$-terminal domain form of $\mathrm{Hh}(\mathrm{HhN})$ is doubly lipid-modified with a cholesterol group on the $\mathrm{C}$-terminus, ${ }^{5}$ and a palmitoyl group on the $\mathrm{N}$-terminus of Hh. ${ }^{67}$ Despite these lipid modifications, Hh moves beyond the cells where it is expressed and the form of $\mathrm{Hh}$ that is diffusible and the mechanism of trafficking is the focus of extensive study. ${ }^{8-14}$ A number of cell surface and extracellular matrix (ECM) molecules have been implicated in modulating Hh diffusion and activity, ${ }_{15}^{15}$ including hedgehoginteracting protein, ${ }^{16}$ interference of hedgehog (ihog) ${ }^{17}$ and heparan sulfate proteoglycans (HSPGs). ${ }^{18-20}$ In the current models for Hh trafficking to the responding cell, Hh proteins are released from cells as lipoprotein-associated oligomers. ${ }^{15,21-23}$ These freely diffusible multimeric forms of $\mathrm{Hh}^{24}$ travel from Hh-producing cells to Hh-responding cells via interactions with HSPGs, including both glypicans ${ }^{20}$ and megalin. ${ }^{25}$

A role for HSPGs in Hh signaling is implicated by restriction in the range of Hh signaling in cells lacking the tout velu gene, which encodes a heparan sulfate 
copolymerase. ${ }^{19}$ The interaction between Shh and HSPGs is critical for cerebellar granule cell proliferation. ${ }^{13}$ Direct binding of Hh to HSPGs in cerebellar sections was demonstrated using immunohistochemical approaches, and binding was prevented by heparinase treatment to remove heparan sulfate side chains. ${ }^{13}$ The dally-like protein, a member of the glypican family, has been implicated in mediating $\mathrm{Hh}$ responsiveness and in $\mathrm{Hh}$ trafficking. ${ }^{26,27} \mathrm{HSPGs}$, in addition to controlling Hh movement through the ECM, may also modulate signaling by influencing the signaling apparatus itself. ${ }^{18,28}$ Recently, genetic studies have demonstrated that glypican-3 binds with high affinity to $\mathrm{Hh}$, and inhibits $\mathrm{Hh}$ signaling by competition with the Hh receptor, Patched (Ptc), for Hh binding. ${ }^{20}$ Mice null for glypican-3 have altered $\mathrm{Hh}$ signaling, as assessed by changes in the downstream effectors Gli1 and Ptc. ${ }^{20}$

The high-affinity association of Hh to another cell surface "receptor" involved in Hh activity, ihog, appears to be promoted by heparin binding. ${ }^{18}$ Interestingly, a sulfated monosaccharide is trapped at the interface of $\mathrm{Hh}$ and ihog. ${ }^{28}$ The ability of Hh proteins to interact with heparin was initially established by demonstrating Hh binding to heparin agarose. ${ }^{13,29,30}$ Furthermore, all Hh proteins were found to possess a consensus (Cardin-Weintraub) sequence ${ }^{31}$ for heparin binding. ${ }^{13}$ This motif is characterized by a cluster of basic residues in the N-terminal region that allows for electrostatic binding with the negative charges of heparin. Mutations and truncations through this motif showed reduced $\mathrm{Hh}$ binding to heparin and reduced $\mathrm{Hh}$ activity. ${ }^{13,29,32} \mathrm{In}$ the $\mathrm{x}$-ray structure of the recombinant sonic Hh N-terminal (ShhN) domain, ${ }^{29}$ the $\mathrm{N}$-terminal sequence possessing this putative heparin binding site is located towards the $\mathrm{N}$-terminus that extends away from the core structure. ${ }^{7}$ Changes in downstream Hh signaling have been observed by studies that reduce HSPG binding to Hh. Mutations through the Cardin-Weintraub sequence of Shh affect the ability of Shh to promote proliferation of cerebellar cells. ${ }^{13}$ The formation of complexes between another HSPG, perlecan, and Shh correlated with increasing metastatic potential of a prostate cancer cell line, and silencing of perlecan expression by siRNA decreased Hh signaling. ${ }^{33}$

Characterization of human tumor samples and cell lines, along with inhibitor studies in animal models, have pointed to a central role for the Hh pathway in the growth of many cancer types, ${ }^{34,35}$ with $\mathrm{Hh}$ signaling now implicated in approximately $20 \%-25 \%$ of all cancers. ${ }^{15,34,36,37}$ Antibodies to Hh were initially used to achieve physiologic blockade of Hh binding and activity. ${ }^{38}$ In many of the Hh-pathway-dependent tumors, natural product Hh pathway inhibitors such as cyclopamine and KAAD-cyclopamine decrease the rate of tumor cell proliferation in vitro and in mouse xenograft models. ${ }^{34}$ These compounds act by binding to the helical bundle of the coreceptor Smoothened (Smo) and inhibiting Hh signaling. ${ }^{39,40}$ Other small molecule Hh pathway inhibitors have been identified from high throughput screening (HTS) of basal cell carcinoma cell lines and these compounds also target Smo. ${ }^{41}$ Subsequent studies with these inhibitors have demonstrated that the use of Hh inhibitors can be a valid therapeutic approach for treating Hh-pathway dependent cancers. ${ }^{42}$ Phenotypic screens have also yielded inhibitors targeting the Hh pathway downstream, and these compounds (GANTs) appear to act by targeting the Hh pathway transcription factor Gli. ${ }^{43-46}$ Thus, these current small molecule inhibitors of the Hh pathway almost exclusively target Smo or Gli, and molecules to alternative targets in the Hh pathway are of great interest.

Enzyme-linked immunosorbent assay and biochip formats have been used to develop assays for heparin binding to other proteins. ${ }^{47-49}$ In this study we describe the development of a simple and robust HTS fluorescence polarization (FP) assay based on the interaction of ShhN with heparin. FP assays have been used extensively to identify small molecule inhibitors of many biologic interactions, including other heparin binding partners, ${ }^{50,51}$ with the application of FP to HTS assays having been recently reviewed. ${ }^{52}$ We expect that molecules that bind directly to Hh protein and block heparin binding will provide a new set of target-based inhibitors that will expand the currently available Hh pathway inhibitors.

\section{Materials and methods \\ Materials}

Black 384-well low-flange, flat-bottom assay plates (Corning, NY) were used. Porcine intestinal mucosa heparins, low molecular weight (LMW) heparins, fluorescently-labeled heparin, and suramin were from Sigma Aldrich (St Louis, MO). All other reagents were of analytical reagent grade. The gene for human ShhN, comprising residues 24-197, was synthesized (Geneart Inc., Burlingame, CA) and subcloned into the pET19b expression vector (Novagen Inc., Madison, WI). Expression and purification was essentially as previously described. ${ }^{29}$

\section{Fluorescence polarization measurements}

Polarization measurements were conducted using a PHER Astar microplate reader (BMG Labtech, Offenburg, Germany) with the FP module. The excitation wavelength was $485 \pm 6 \mathrm{~nm}$ and emission was detected at $520 \mathrm{~nm} \pm 15 \mathrm{~nm}$. For each 
experiment, the gain of the parallel and perpendicular channels was calibrated such that the fluorescent tracer had a polarization value of $\sim 35$ millipolarization units $(\mathrm{mP})$.

\section{Fluorescence polarization assays}

The FP assay was performed in black 384-well plates. Unless stated, the FP assay buffer was $20 \mathrm{mM}$ sodium phosphate $\mathrm{pH} 6.5,150 \mathrm{mM} \mathrm{NaCl}$, with $0.5 \mathrm{mM}$ of DTT added for ShhN dilutions. For each FP assay, $25 \mu \mathrm{L}$ of ShhN at various concentrations were added to each well and a preincubation time of 10 minutes was set. Then $25 \mu \mathrm{L}$ of $20 \mathrm{nM}$ heparin-fluorescein conjugate (flu-heparin) was added; after 10 minutes of coincubation, the FP values were read. The final volume per well was $50 \mu \mathrm{L}$. All assays were performed in triplicate.

For competition assays, $1 \mu \mathrm{L}$ each of heparin unlabeled salt or suramin at different concentrations and $25 \mu \mathrm{L}$ of $200 \mathrm{nM}$ ShhN were preincubated for 10 minutes before adding the flu-heparin tracer. For blank measurements, a mixture containing the same components (except the labeled heparin) was used. All measurements were performed in a final dimethyl sulfoxide (DMSO) concentration of $1 \%$.

\section{FP data analysis}

The FP values were expressed in $\mathrm{mP}$ units. Data analysis was conducted using PHERAstar software V1.60 (BMG Labtech, Germany), as well as GraphPad Prism v5.0 (GraphPad Software Inc., San Diego, CA). All dissociation constants $\left(\mathrm{K}_{\mathrm{D}}\right)$ and inhibition constants $\left(\mathrm{IC}_{50}\right)$ values were determined using nonlinear regression.

\section{Automation}

The validation experiments were performed using Multidrop ${ }^{\circledR}$ 384 bulk dispensers (ThermoScientific, Hudson, NH) for assay additions and a Biomek ${ }^{\circledR}$ NX (Beckman Coulter Inc., Fullerton, CA) for DMSO/compound additions to 384-well plates.

\section{Estimation of assay quality}

The Z' factor was used to assess the quality of the assay and estimate the screening window. ${ }^{53}$ The Z' factor incorporates both the dynamic range of the assay as well as well-to-well variability. Values are obtained by running one whole 384-well plate of maximum (max) signal control and one whole 384-well plate of minimum (min) signal control. Z' factor was calculated using the formula:

$$
\mathrm{Z}^{\prime}=1-\left(3 \mathrm{SD}_{\text {max }}+3 \mathrm{SD}_{\min }\right) /\left(\text { mean }_{\max }-\text { mean }_{\min }\right)
$$

Where $\mathrm{SD}=$ standard deviation, $\max =$ maximum signal, $\min =$ minimum signal.

\section{Cell-based assay for hedgehog activity}

The pluripotent mesenchymal cell line C3H10T1/2 was obtained from ATCC (Manassas, VA) and maintained in Dulbecco's modified Eagle medium containing 10\% fetal bovine serum. The assay was performed essentially as described previously, ${ }^{29}$ with cells plated in 96-well plates at 5000 cells/well. Twenty-four hours later, $\mathrm{ShhN}$ protein was added and the cells were incubated for a further four days. Cells were then lyzed and assayed for alkaline phosphatase (AP) activity (a marker for differentiation into an osteoblast lineage) using the chromogenic substrate pNPP and read at $405 \mathrm{~nm}$. Typical dose responses were carried out in the range of 0.1 to $10 \mu \mathrm{g} / \mathrm{mL}$ ShhN protein. The $\mathrm{EC}_{50}$ value is defined as the concentration of ligand giving half maximal activity.

For competition experiments, ShhN was kept at a fixed concentration of $2.0 \mu \mathrm{g} / \mathrm{mL}$, and various concentrations of competitors were added directly in the wells containing cells. Half maximal effective concentration $\left(\mathrm{EC}_{50}\right)$ constant and inhibition constant $\left(\mathrm{IC}_{50}\right)$ values were determined in GraphPad 5.0 with nonlinear regression.

\section{Results \\ Detection of ShhN-heparin binding using fluorescence polarization}

Direct binding of Hh to heparin has been demonstrated previously using surface plasmon resonance (SPR) ${ }^{49}$ and chromatographic formats. ${ }^{30}$ As a more amenable HTS assay, we have assessed the feasibility of using the homogeneous FP format as the basis for developing a simple and robust primary assay for identifying inhibitors of the Hh-heparin interaction. Polarization experiments were conducted in 384-well plates using flu-heparin and purified ShhN domain. A schematic for the FP assay is shown in Figure 1. Binding of the flu-heparin tracer to ShhN leads to an increase in the size of the flu-labeled complex and a decrease in rotational motion that results in the emitted light being polarized and higher $\mathrm{mP}$ values. Addition of molecules that block the $\mathrm{ShhN} /$ flu-heparin interaction will result in a lowered $\mathrm{mP}$ signal.

For optimal sensitivity, the flu-heparin concentration was set to produce a total fluorescence signal-to-background ratio greater than 20, and this required a concentration of $>5 \mathrm{nM}$ (Figure 2a) and results in a constant tracer signal of $\sim 50 \mathrm{mP}$ (Figure 2b). To establish an assay for ShhN binding to 


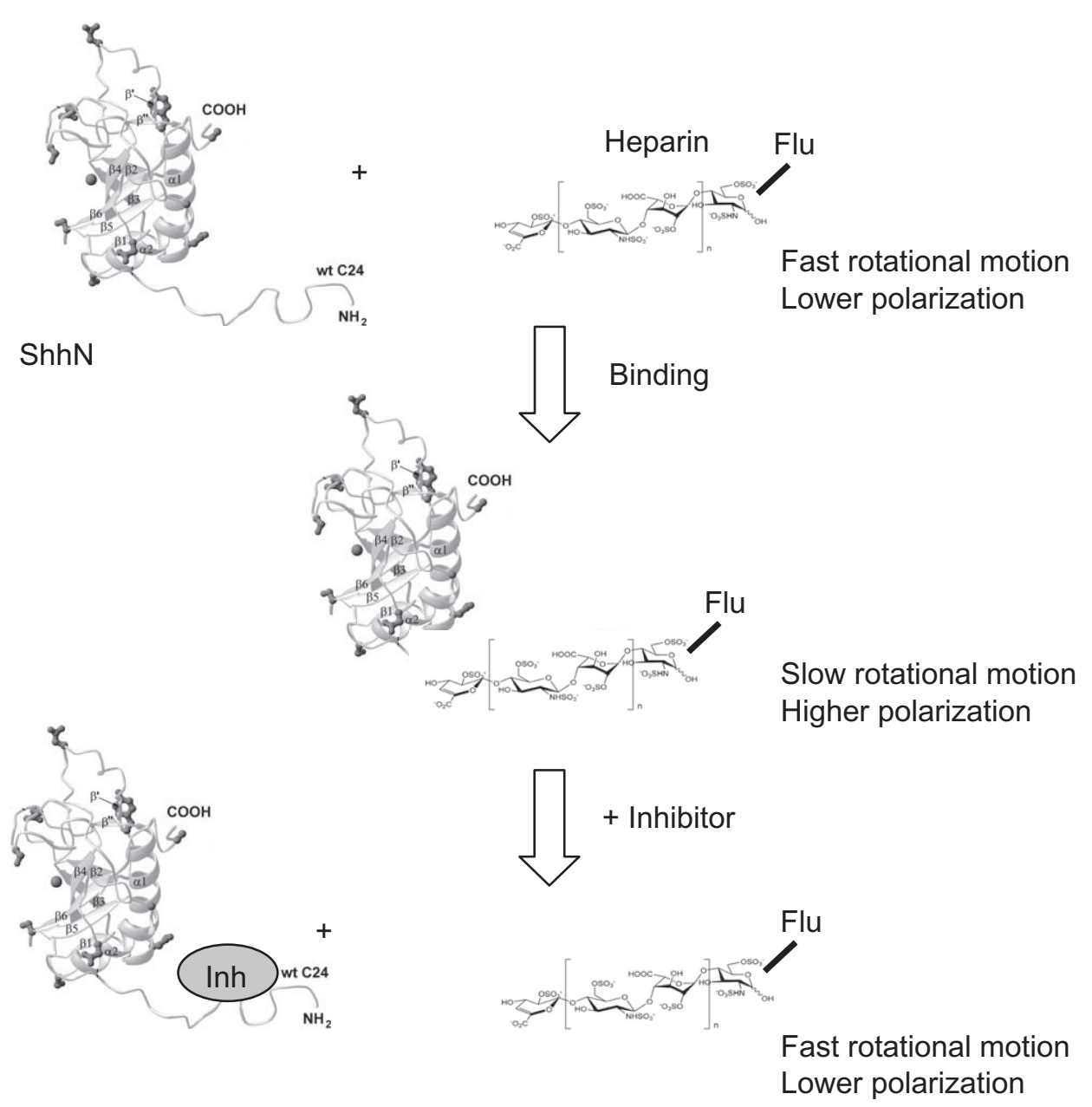

Figure I Schematic illustration of a hedgehog-heparin FP assay.*Rotational motion of the flu-heparin will be reduced upon binding to ShhN, resulting in an increase in light polarization. Inh that bind $\mathrm{ShhN}$ at the heparin binding site will result in an increase in free flu-heparin and a concomitant decrease in light polarization.

Notes: *ShhN crystal structure figure adapted from Pepinsky et $\mathrm{al}^{7}$ and heparin schematic from Zhang et al. ${ }^{49}$

Abbreviations: Flu, fluorescently-labeled; FP, fluorescence polarization; Inh, inhibitors; ShhN, sonic hedgehog N-terminal domain.

flu-heparin, we first incubated increasing concentrations of ShhN protein with a fixed amount of flu-heparin to assess for saturation binding. When ShhN was added to flu-heparin, a rapid increase in the measured polarization was observed over the polarization of free flu-heparin, with the polarization value reaching a plateau at 10 minutes and remaining constant for at least one hour (Figure 3a).

A saturation binding isotherm constructed by plotting ShhN concentration against $\mathrm{mP}$ values shows that $\mathrm{ShhN}$ binds flu-heparin in a dose-dependent manner (Figure 3b). As the concentration of $\mathrm{ShhN}$ was increased, $\mathrm{mP}$ values increased until saturation was reached (Figure $3 \mathrm{~b}$ ). Saturating amounts of ShhN caused an increase in FP of $\sim 75 \mathrm{mP}$. Nonlinear regression analysis (single-site binding model) was used to fit the data, and an apparent $K_{D}$ value of $99 \mathrm{nM}$ was determined. This value fits well with that previously reported for murine ShhN binding to heparin using an SPR format $\left(\mathrm{K}_{\mathrm{D}}=67 \mathrm{nM}\right) .{ }^{49}$ We would suggest that in our assay, high-affinity heparin binding is occurring primarily with the polybasic stretch of residues localized on the N-terminal part of ShhN (residues 32-38), because we have previously demonstrated that truncating ${ }^{29}$ or mutating ${ }^{29,32}$ this region affects Hh activity, including heparin binding.

The $\mathrm{pH}$ dependence and DMSO tolerance of the assay was also assessed. Flu-heparin binding to ShhN was the highest at $\mathrm{pH}$ 5.5-6.5 and decreased at $\mathrm{pH} 7.4$ (data not shown). The final concentration of DMSO in the assay is critical because most compound libraries are initially solubilized in $100 \%$ DMSO then subsequently diluted in an aqueous buffer. Our preferred HTS scheme involves $0.5 \mu \mathrm{L}$ of the compounds being prespotted in 384-well plates with a final assay volume of $50 \mu \mathrm{L}$. Master compound plates are $1 \mathrm{mM}$ stock concentration in $100 \%$ DMSO. Hence the effect of $1 \%(\mathrm{v} / \mathrm{v})$ DMSO was tested in the assay and was found not to affect $\mathrm{Hh} / \mathrm{flu}-$ heparin binding (data not shown). All subsequent assays were performed at a constant $1 \%$ DMSO concentration. 
A

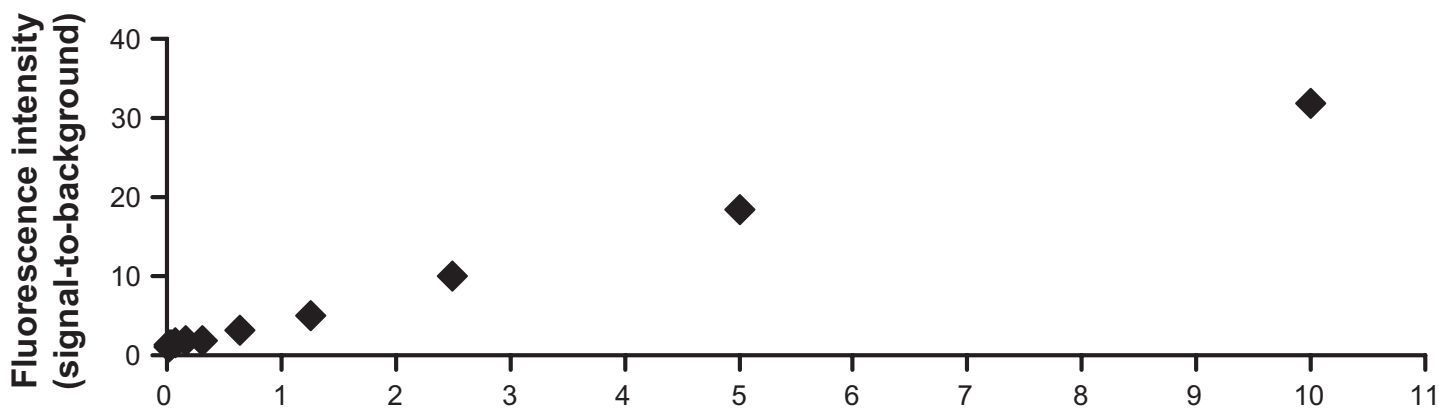

[Flu-heparin] (nM)

B

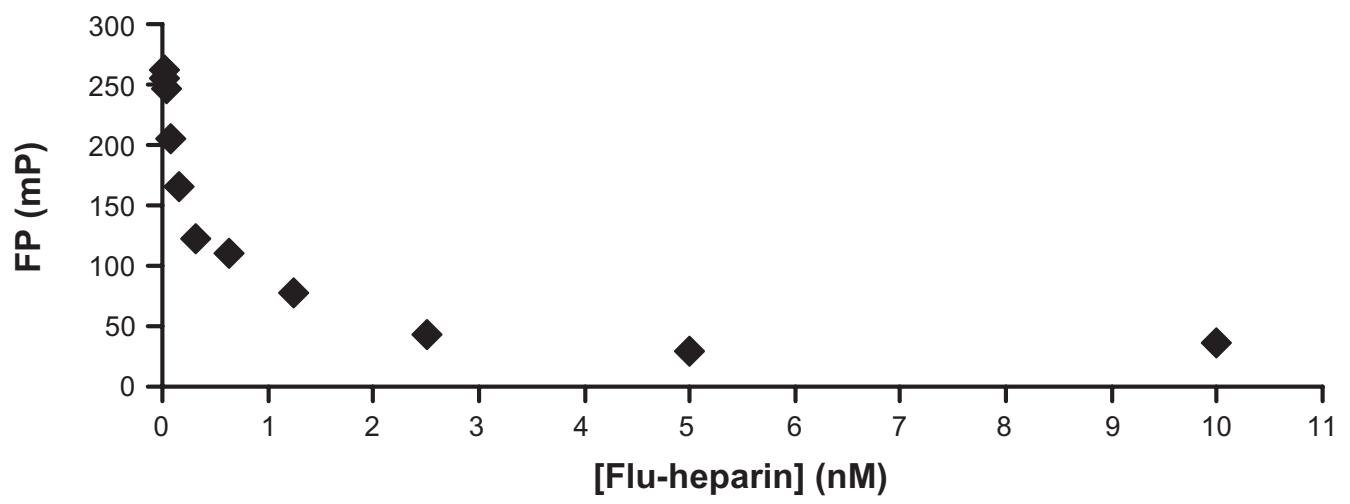

Figure 2 Flu-heparin tracer optimization. A) Flu-heparin was serially diluted in a 384-well plate. Signal-to-background was calculated as the fluorescence intensity in the presence of labeled flu-heparin divided by the fluorescence of buffer. B) The FP signal was measured and average values plotted against flu-heparin concentration. Abbreviations: Flu, fluorescently-labeled; FP, fluorescence polarization.

\section{Fluorescence polarization competitive binding studies}

For competition binding assays, the concentrations of fluheparin and ShhN were set to give $\sim 50 \%$ of the maximal response to provide good assay sensitivity. ${ }^{54}$ Unlabeled heparins of varying molecular weights were assessed as competitors. Addition of various concentrations of the unlabeled 13,000 MW heparin to a mixture of $20 \mathrm{nM}$ fluheparin and $100 \mathrm{nM} \mathrm{ShhN} \mathrm{resulted} \mathrm{in} \mathrm{a} \mathrm{dose-dependent}$ decrease in polarization and a calculated $\mathrm{IC}_{50}$ value of $240 \mathrm{nM}$ (Figure 4a). The heparin molecules tested had differing $\mathrm{IC}_{50}$ values in the assay, with a correlation found between higher molecular weight of the heparin and better inhibition (Figure $4 \mathrm{~b}$ ). These findings are consistent with the SPR studies ${ }^{49}$ indicating that heparin and LMW heparin had differing $\mathrm{IC}_{50}$ values of 50 and $700 \mathrm{nM}$, respectively, for blocking heparin binding to mouse $\mathrm{ShhN}$, and that heparins must be larger than an octasaccharide to block Shh-heparin binding. ${ }^{49}$

To assess whether a small molecule could block fluheparin binding to ShhN, we tested the polyanionic compound, suramin (molecular weigh 1429.17 Da), which has been previously shown to be a competitive inhibitor of the other heparin-binding proteins. ${ }^{55}$ We tested suramin in the FP assay for its ability to block the ShhN-heparin interaction (Figure 5). Suramin inhibited this interaction in the FP assay, with an $\mathrm{IC}_{50}$ value of $4.6 \mu \mathrm{M}$, indicating that small molecules could be identified as inhibitors of Hh-heparin binding.

\section{Heparins inhibit ShhN function in the Hh-dependent C3HTI0I/2 cell assay}

The mouse embryonic fibroblast line $\mathrm{C} 3 \mathrm{H} 10 \mathrm{~T} 1 / 2$ has been used extensively as an in vitro model and provides a simple system for assessing Hh activity. This cell line is Hh-responsive as 


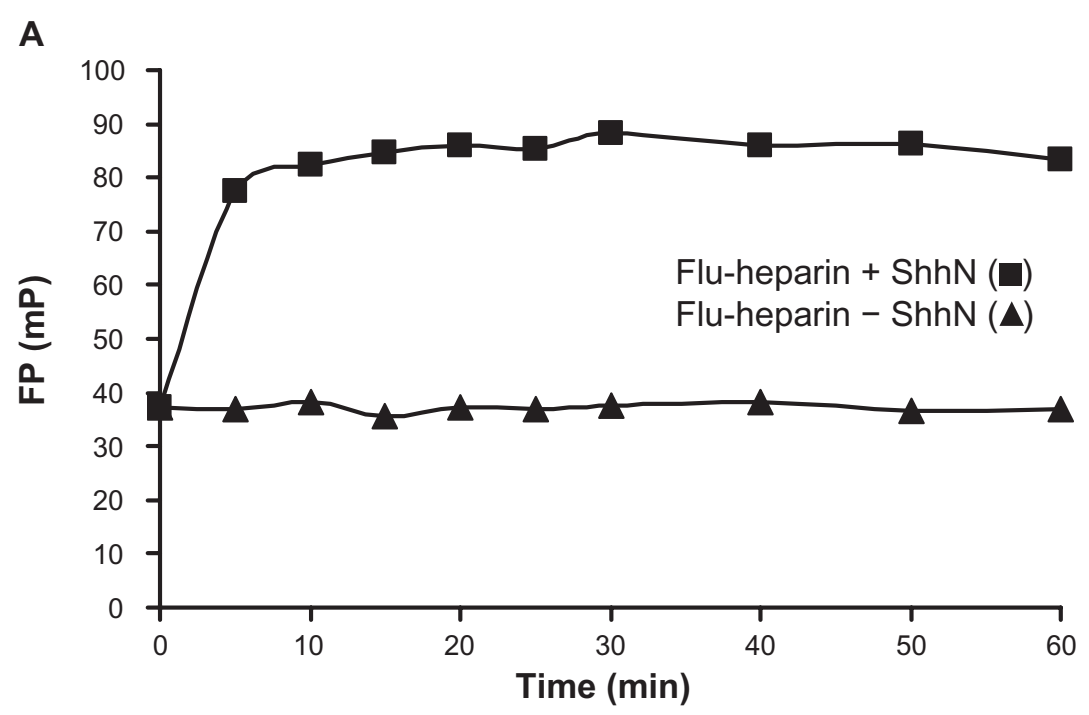

B

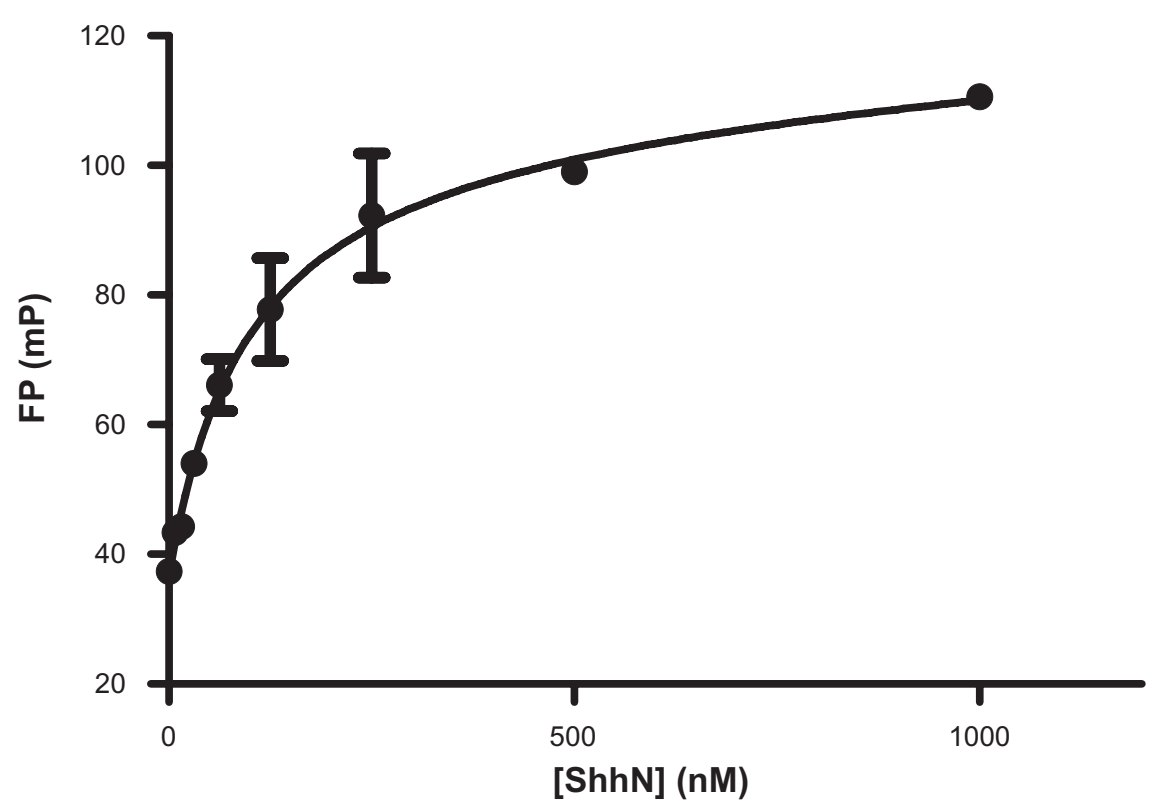

Figure 3 Binding of flu-heparin to ShhN. A) Time course of flu-heparin binding to ShhN. Flu-heparin binding was monitored as the increase in polarization using $10 \mathrm{nM}$

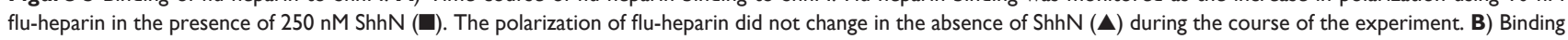
isotherm for flu-heparin binding to ShhN. Increasing concentrations of ShhN were incubated with flu-heparin (20 nM) for 10 minutes after which FP was measured. Data were analyzed and plotted in Prizm 5.0.

Abbreviations: Flu, fluorescently-labeled; FP, fluorescence polarization; ShhN, sonic hedgehog N-terminal domain.

assessed by induction of AP, and has been used by our research group to assess the activity of recombinant $\mathrm{Hh}$ proteins ${ }^{29}$ and as an assay for inhibitors of Hh signaling. ${ }^{29,38}$ In this assay, ShhN had an $\mathrm{EC}_{50} \sim 2 \mu \mathrm{g} / \mathrm{mL}$ (data not shown). The ability of heparins of varying molecular weights to inhibit Hh activity was also tested in the C3H10T1/2 cell line AP induction assay.

Heparin titrations were made in media, and media alone was used as the negative control. Addition of varying concentrations of the unlabeled 13,000 molecular weight heparin to C3H10T1/2 cells in the presence of $2 \mu \mathrm{g} / \mathrm{mL}$ ShhN resulted in a dose-dependent decrease in AP activity and a calculated
$\mathrm{IC}_{50}$ value of $2.56 \mu \mathrm{M}$ (Figure 6a). The heparins inhibited $\mathrm{Hh}$ activity in this assay with varying $\mathrm{IC}_{50}$ values (Figure $6 \mathrm{~b}$ ), and a correlation between the $\mathrm{IC}_{50}$ values for heparin inhibition in the FP assay (Figure $4 \mathrm{~b}$ ), and the $\mathrm{IC}_{50}$ values for heparin inhibition in the $\mathrm{C} 3 \mathrm{H} 10 \mathrm{~T} 1 / 2$ bioassay (Figure $6 \mathrm{~b}$ ) suggest that this assay will be a good secondary assay to identify small molecule inhibitors that block Hh-heparin binding and Hh activity.

\section{Assay variability}

The variability of the ShhN/flu-heparin FP was studied using triplicate 384-well DMSO plates in a typical 
A

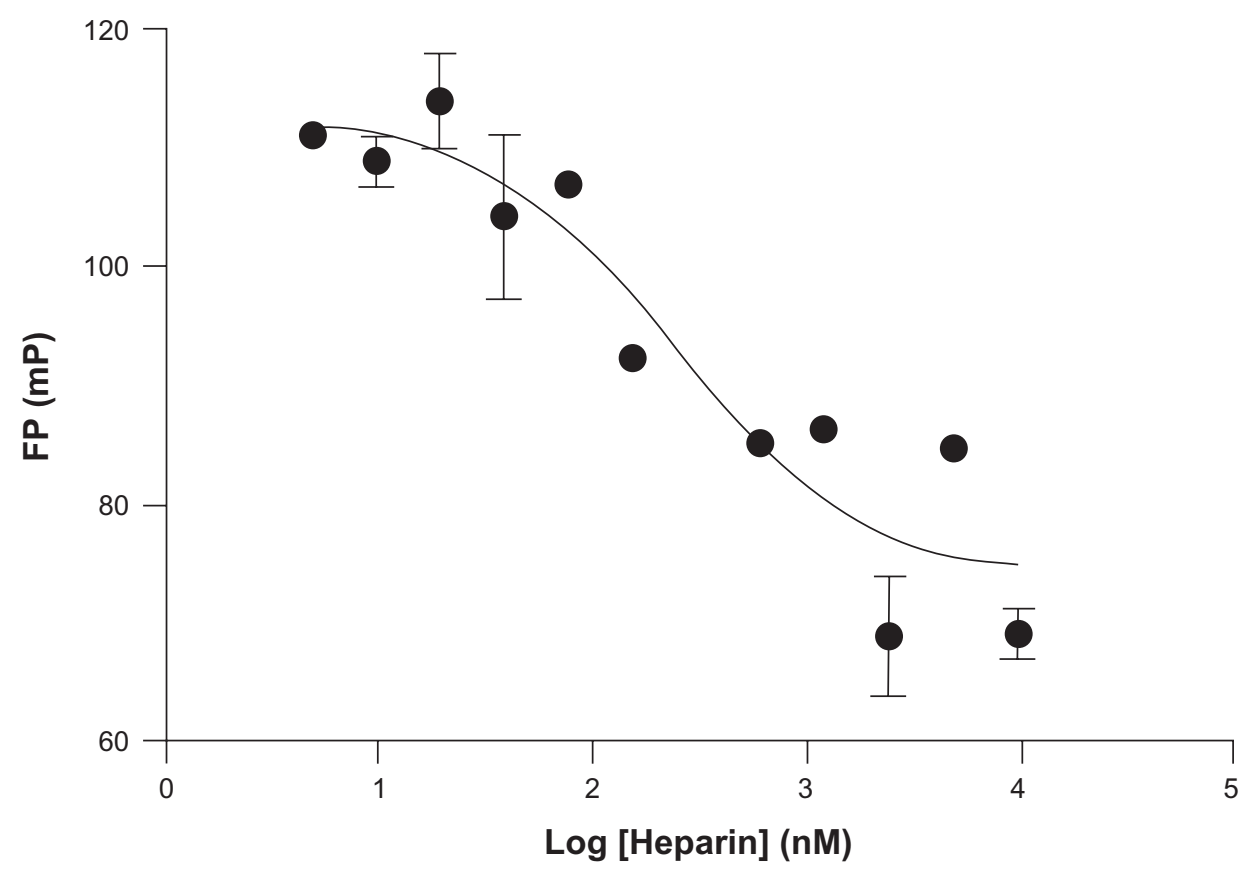

B

\begin{tabular}{|c|c|c|c|c|}
\cline { 2 - 5 } \multicolumn{1}{c|}{} & \multicolumn{4}{c|}{ Heparin MW (Da) } \\
\cline { 2 - 5 } \multicolumn{1}{c|}{} & 3,000 & 5,000 & $\begin{array}{l}4,000 \\
6,000\end{array}$ & 13,000 \\
\hline$I_{50}(\mu \mathrm{M})$ & $>10$ & 1.16 & 0.69 & 0.24 \\
\hline
\end{tabular}

Figure 4 Competitive displacement of ShhN/flu-heparin interaction by unlabeled heparins. A) Competitive inhibition of ShhN/flu-heparin binding by heparin (13,000 Da) in the FP assay. Increasing concentrations of heparin were incubated with $\mathrm{ShhN}(100 \mathrm{nM})$ and flu-heparin $(20 \mathrm{nM})$ for 10 minutes after which FP was measured. B) Calculated $I_{50}$ values for the four heparins tested as competitive inhibitors in the FP assay. Data were analyzed and plotted in Prizm 5.0.

Abbreviations: Flu, fluorescently-labeled; FP, fluorescence polarization; ShhN, sonic hedgehog N-terminal domain; MW, molecular weight.

"Min-Mid-Max" experiment and determining Z"53 as a measure of assay quality (Figure 7a). For this HTS version of the assay (Table 1), the ShhN/flu-heparin assay was simplified into an assay consisting of two $25 \mu \mathrm{L}$ addition steps using Multidrop 384 (Thermo Fisher) bulk dispensers. DMSO plates were used as a preliminary simulation of compound plates. All plates were prespotted with $0.5 \mu \mathrm{L}$ DMSO using a Biomek NX liquid-handling work station. ShhN was added first, incubated with DMSO for 10 minutes, followed by addition of flu-heparin, and a further 10-minute incubation prior to reading the plates. Initial experiments were conducted to evaluate the robustness of the assay window by measuring statistically significant changes in $\mathrm{mP}$ values between no Shh (minimum signal), $50 \mathrm{nM} \mathrm{Shh}\left(<\mathrm{K}_{\mathrm{D}}\right)$, and $100 \mathrm{nM}$ Shh $\left(\sim \mathrm{K}_{\mathrm{D}}\right)$. The data yielded a calculated Z' factor for individual plates of 0.56 and a coefficient of variation $<10 \%$ (Figure 7b), demonstrating a suitable assay window and acceptable variability for HTS. The assay was repeated for a second day with comparable results for Z' and the coefficient of variation (Figure $7 \mathrm{~b}$ ).

\section{Discussion}

The Hh family of secreted signaling proteins plays a major role in embryonic development and in the development of many cancers. There is growing evidence that HSPGs play a direct role in Hh signaling and diffusion. 


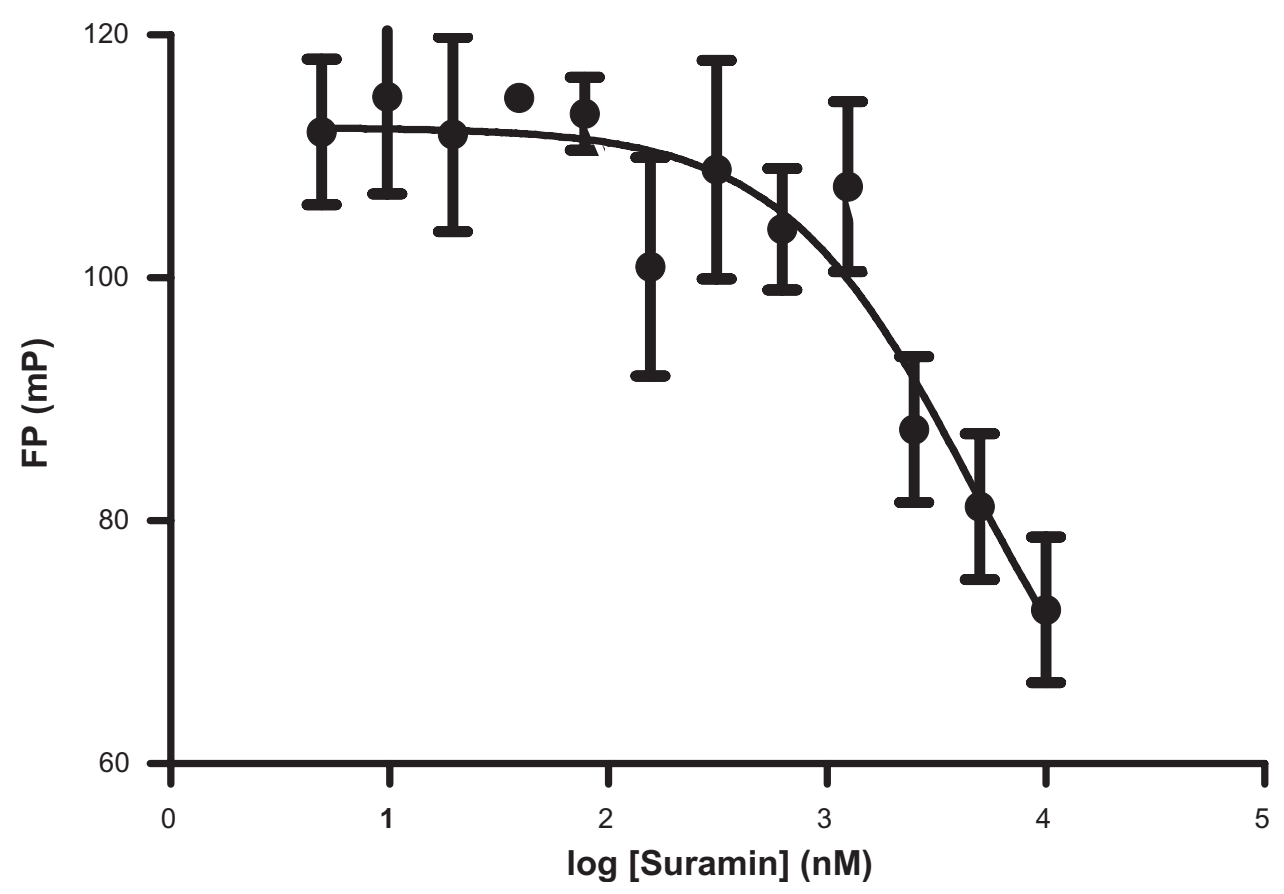

Figure 5 Suramin is a competitive inhibitor of the ShhN/flu-heparin interaction. Increasing concentrations of suramin were added to the FP assay containing flu-heparin $(20 \mathrm{nM})$ and $\mathrm{ShhN}(100 \mathrm{nM})$ and following incubation for 10 minutes FP values were measured. Data were analyzed and plotted in Prizm 5.0.

Abbreviations: Flu, fluorescently-labeled; FP, fluorescence polarization; ShhN, sonic hedgehog N-terminal domain.

Although HSPGs facilitate the activity of a number of signaling systems, there are few examples of modulators targeting these interactions. Our goal is to identify novel inhibitors of the Hh pathway by targeting the interaction of Hh ligand with HSPGs using Hh-heparin as a model system. First, as described here, we have designed an HTS assay structured to identify molecules that can modulate heparin-Hh interactions. The study presented here provides a simple FP-based assay for measuring the interaction of Hh ligand with heparin and identifying molecules that disrupt this interaction. The FP format was chosen as the basis for developing an Hh-heparin assay for HTS because FP is suitable for measuring protein-HSPG binding and has been used previously to develop an FP HTS assay for heparin-fibroblast growth factor binding. ${ }^{51} \mathrm{FP}$ is also a homogeneous format that allows a relatively simple "mix and read" automation scheme and is less susceptible to interference by fluorescence compounds, a frequent cause of false positives in HTS assays. ${ }^{56}$

Using our FP-based format, we have demonstrated highaffinity binding of Shh to heparin $\left(\mathrm{K}_{\mathrm{D}} \sim 100 \mathrm{nM}\right)$ and that unlabeled heparins compete for binding, with increasing heparin size correlating with better inhibition. This finding is consistent with previously published studies reporting that the minimum oligosaccharide size for competing for ShhN binding to heparin must be larger than an octasaccharide. ${ }^{49}$
The feasibility of identifying small molecules that block ShhN-heparin interactions is shown here by (i) the ability of suramin to block ShhN-flu-heparin binding in our FP assay and (ii) by a reported HTS assay for inhibitors of fibroblast growth factor receptor binding to heparin that identified several potent small molecule inhibitors. ${ }^{51}$ Suramin was also a weak inhibitor of Hh activity in the $\mathrm{C} 3 \mathrm{H} 10 \mathrm{~T} 1 / 2$ assay with an $\mathrm{IC}_{50}$ value more than $\sim 100 \mu \mathrm{M}$ (data not shown). Hence, we observed a correlation between the FP and C3H10T1/2 assays for both the heparin and suramin molecules, with inhibition values in the FP assay approximately five- to 10-fold lower than in the C3H10T1/2 assay.

The Hh-heparin FP assay described in the present study is robust and meets criteria for industry-accepted HTS standards $\left(Z^{\prime}>0.5\right)$. To maximize the potential number of hits from a HTS run, the FP assay format was developed and validated, with DMSO or compounds prespotted, followed by ShhN incubation for 10 minutes, followed by flu-heparin addition and 10 minutes' incubation prior to reading the plate. To address whether these hits also disrupt ShhN already bound to heparin, we plan to use a secondary assay to screen hits versus preformed $\mathrm{ShhN} /$ flu-heparin complexes. The unmodified form of ShhN rather than the physiologic doubly lipid-modified $\mathrm{ShhN}^{6}$ was used in our FP assay because we could produce the former in amounts sufficient to run a full HTS of 100,000 compounds. Because 


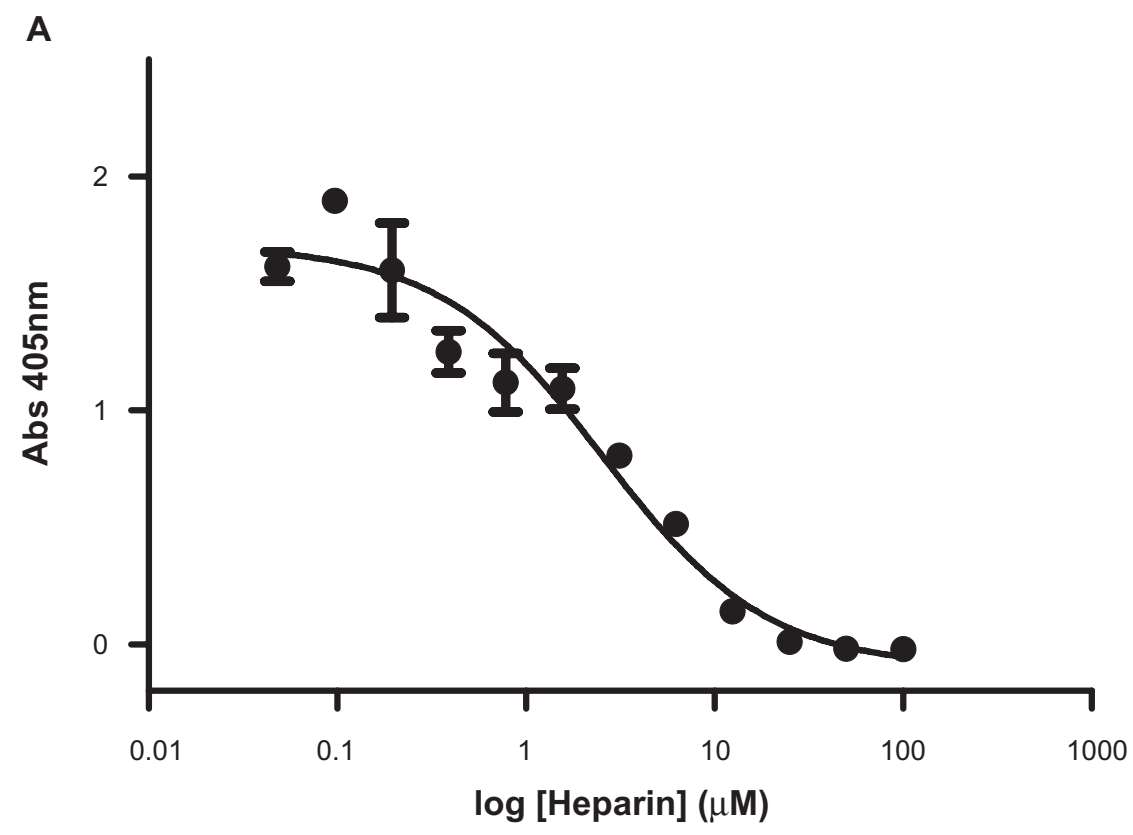

B

\begin{tabular}{|c|c|c|c|c|}
\hline & \multicolumn{4}{|c|}{ Heparin MW (Da) } \\
\hline & 3,000 & 5,000 & $\begin{array}{c}4,000- \\
6,000\end{array}$ & 13,000 \\
\hline $\mathrm{IC}_{50} \mu \mathrm{M}$ (BioAssay) & 54 & 17.41 & 11.49 & 2.56 \\
\hline
\end{tabular}

Figure 6 Heparins block ShhN-mediated induction of AP in the Hh-responsive cell line C3HI0TI/2. A) Serial dilutions of heparin (I3,000 Da) were incubated with the

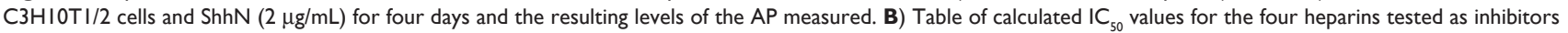
in the C3HI0TI/2 cell assay. Data were analyzed and plotted in Prizm 5.0.

Abbreviation: Abs, absorbance; AP, alkaline phosphatase; hh, hedgehog; ShhN, sonic hedgehog N-terminal domain; MW, molecular weight.

we can only produce the lipid-modified form in very limited amounts in a mammalian cell line, our plan is to use the doubly lipid-modified Shh in a secondary assay to assess whether hits also block binding of heparin to this form of Hh.

Due to the nature of heparin-Hh binding through a charged motif, we would expect to observe a number of false positives in this assay from a primary screen. Hence, after identifying hits from an HTS screen, we plan to use a panel of complementary secondary and counterscreen assays to eliminate unwanted activities, and identify those compounds that work by selectively blocking Hh-HSPG binding. Confirmed hits from HTS would first be counterscreened using a biologically unrelated FP assay that we have previously described measuring fluorescein-peptide binding to heat shock protein $70 .{ }^{57}$ This counterscreen should eliminate compounds that nonspecifically interfere in FP assays. It is also expected that a number of highly charged compounds will be selected as Hh-heparin inhibitors from HTS that may act to inhibit all heparin binding interactions. We plan to use a published assay measuring heparin-fibroblast growth factor binding $^{51}$ as a secondary selectivity assay. Compounds that selectively block Hh binding to heparin but not the binding of fibroblast growth factor to heparin would be prioritized for further study.

Evidence is mounting that a requirement for abnormal expression of Hh is characteristic of a number of types of cancers and has been reported for small-cell lung ${ }^{58}$ pancreatic, ${ }^{59}$ oesophageal,${ }^{60}$ prostate, ${ }^{37,61}$ breast, ${ }^{62,63}$ colon, ${ }^{64,65}$ and liver ${ }^{66}$ cancers. The few current inhibitors identified to date for the Hh pathway almost exclusively bind to the Smo coreceptor or target the Gli transcription factors, and so molecules directed to alternative targets in the Hh pathway are of great interest. We expect that the assay described herein will yield 
A

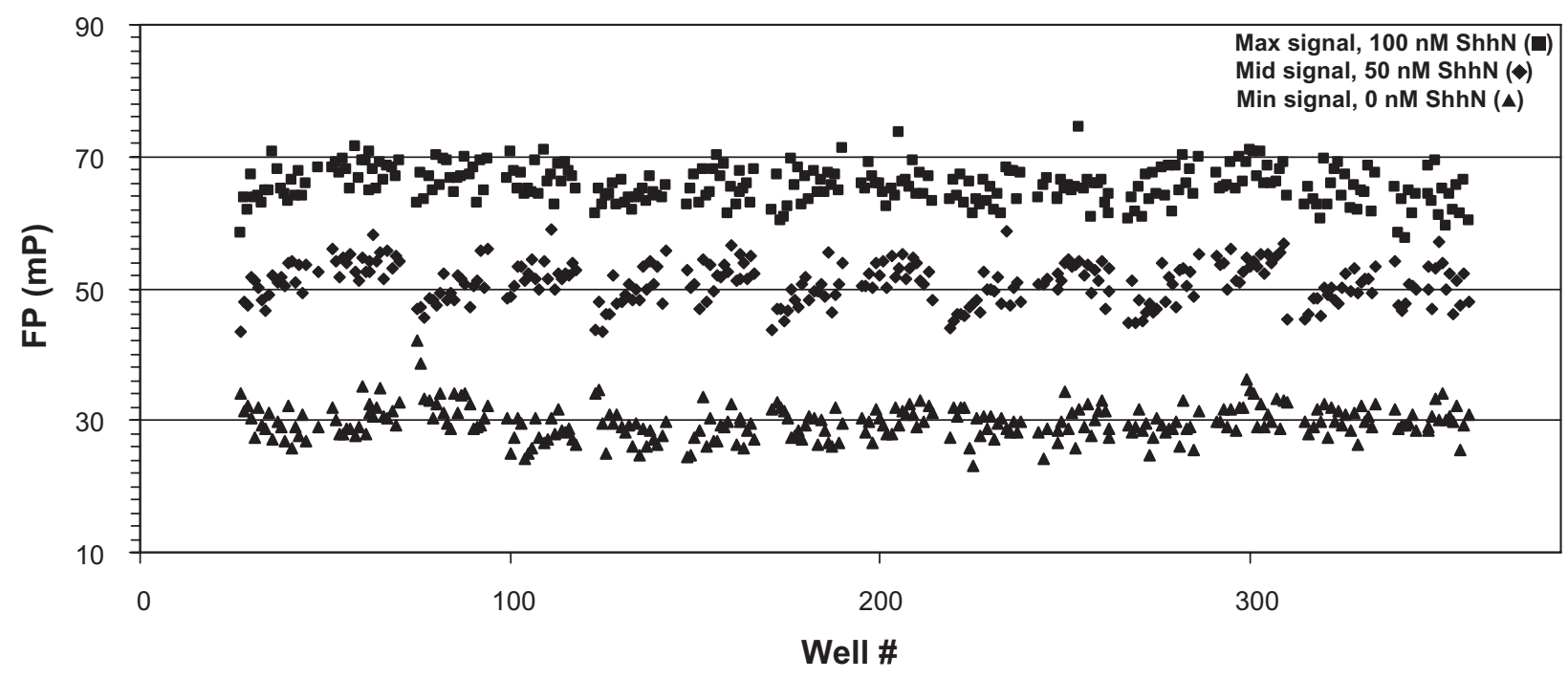

B

\begin{tabular}{|l|r|r|r|}
\hline & \multicolumn{3}{|c|}{ Day 1 } \\
\hline & \multicolumn{1}{|l|}{ Min } & Mid & Max \\
\hline & & & \\
\hline average & 29.71 & 50.87 & 65.68 \\
\hline std & 2.50 & 3.06 & 2.75 \\
\hline CV & 8.40 & 6.02 & 4.19 \\
\hline & & & \\
\hline Z'-factor & & & 0.56 \\
\hline & & & \\
\hline
\end{tabular}

\begin{tabular}{|l|c|c|c|} 
& \multicolumn{3}{|c|}{ Day 2 } \\
\hline & Min & Mid & Max \\
\hline & & & \\
\hline average & 27.90 & 50.11 & 63.49 \\
\hline std & 2.39 & 4.88 & 2.75 \\
\hline CV & 8.56 & 9.74 & 4.34 \\
\hline & & & \\
\hline Z'-factor & & & 0.57 \\
\hline & & & \\
\hline
\end{tabular}

Figure $7 \mathrm{ShhN/flu-heparin} \mathrm{FP} \mathrm{assay} \mathrm{variability} \mathrm{assessment.} \mathrm{A)} \mathrm{FP} \mathrm{assay} \mathrm{validation.} \mathrm{384-well} \mathrm{plates} \mathrm{were} \mathrm{pre-spotted} \mathrm{with} 0.5 \mu \mathrm{L}$ of DMSO using a Biomek NX. One plate each was used to determine the maximum signal $(\boldsymbol{\square})$, mid signal $(\bullet)$ and minimum signal $(\mathbf{\Delta})$. Using a Multidrop $384,25 \mu \mathrm{L}$ of the FP assay buffer was dispensed into the Min plate; for the Mid plate $25 \mu \mathrm{L}$ of $50 \mathrm{nM}$ ShhN was used; and for the Max plate $25 \mu \mathrm{L}$ of $100 \mathrm{nM}$ ShhN was added. After 10 minutes of preincubation, $25 \mu \mathrm{L}$ of $40 \mathrm{nM}$ fluheparin was dispensed. The FP values were obtained after 10 minutes of coincubation. The data represent mP values measured in individual wells, consisting of 320 replicates for each condition. The experiment was performed independently on two different days. B) The variability for inhibition was determined from the maximum and minimum plates. Z' factors, stds, and CVs were calculated in Excel.

Abbreviations: Flu, fluorescently-labeled; FP, fluorescence polarization; ShhN, sonic hedgehog N-terminal domain; CV, coefficient of variance; std, standard deviation.

molecules that bind directly to Hh protein and disrupt HSPG binding, and so will provide a new set of target-based inhibitors that will complement currently available Hh pathway inhibitors. The feasibility of targeting the Hh ligand directly was demonstrated by the recent identification of a natural product-like compound that blocks Hh binding to Ptc, although the binding site for the molecule on Hh has not yet been identified. ${ }^{67}$ It is possible that compounds identified from a screen of the Hh-heparin FP assay described in this study could eventually lead to therapeutics for the treatment of cancers, such as pancreatic and liver, which are driven by Hh overexpression and with few current treatment options.

Table I Automation protocol for ShhN/flu-heparin FP assay

\begin{tabular}{llll}
\hline Step & Event & Parameter & Description \\
\hline $\mathrm{I}$ & Pre-spot & $0.5 \mu \mathrm{l}$ & Dispense DMSO/test compound to 384-well plates using Biomek NX \\
2 & Add & $25 \mu \mathrm{l}$ & Add ShhN to 384-well plates using Multidrop 384 \\
3 & Incubate & $10 \mathrm{~min}$ & Room temperature \\
4 & Add & $25 \mu \mathrm{l}$ & Add flu-heparin to 384-well plates using Multidrop 384 \\
5 & Incubate & $10 \mathrm{~min}$ & Room temperature \\
6 & Read & FP & BMG PheraStar plate reader \\
\hline
\end{tabular}

Abbreviations: DMSO, dimethyl sulfoxide; flu, fluorescently-labeled; FP, fluorescence polarization; ShhN, sonic hedgehog N-terminal domain. 


\section{Acknowledgments}

The authors would like to thank David Lamson, Kamalika Chakrabarty, Ginger Smith, and Mark Hughes at the Biomanufacturing Research Institute and Technology Enterprise Institute (North Carolina Central University) for their technical assistance. This work was supported in part by a grant from the Golden LEAF Foundation and funds from the State of North Carolina.

\section{Disclosure}

The authors declare no conflict of interest in this work.

\section{References}

1. Ingham $\mathrm{P}, \mathrm{McM}$ ahon $\mathrm{A}$. Hedgehog signaling in animal development: Paradigms and principles. Genes Dev. 2001;15(23):3059-3087.

2. Jia J, Jiang J. Decoding the hedgehog signal in animal development. Cell Mol Life Sci. 2006;63(11):1249-1265.

3. McMahon A, Ingham P, Tabin C. Developmental roles and clinical significance of hedgehog signaling. Curr Top Dev Biol. 2003;53:1-114.

4. Pathi S, Pagan-Westphal S, Baker D, et al. Comparative biological responses to human Sonic, Indian, and Desert hedgehog. Mech Dev. 2001;106(1-2):107-117.

5. Porter J, Ekker S, Park W, et al. Hedgehog patterning activity: Role of a lipophilic modification mediated by the carboxy-terminal autoprocessing domain. Cell. 1996;86(1):21-34.

6. Pepinsky R, Zeng C, Wen D, et al. Identification of a palmitic acidmodified form of human sonic hedgehog. J Biol Chem. 1998;273(22): 14037-14045.

7. Pepinsky R, Rayhorn P, Day E, et al. Mapping sonic hedgehog-receptor interactions by steric interference. J Biol Chem. 2000;275(15) 10995-11001.

8. Callejo A, Torroja C, Quijada L, Guerrero I. Hedgehog lipid modifications are required for hedgehog stabilization in the extracellular matrix. Development. 2006;133(3):471-483.

9. Dawber R, Hebbes S, Herpers B, Docquier F, van den Heuvel M. Differential range and activity of various forms of the hedgehog protein BMC Dev Biol. 2005;5:21.

10. Guerrero I, Chiang C. A conserved mechanism of hedgehog gradient formation by lipid modifications. Trends Cell Biol. 2007; 17(1):1-5.

11. Panáková D, Sprong H, Marois E, Thiele C, Eaton S. Lipoprotein particles are required for hedgehog and wingless signaling. Nature. 2005;435(7038):58-65.

12. Taylor F, Wen D, Garber E, et al. Enhanced potency of human sonic hedgehog by hydrophobic modification. Biochemistry. 2001;40(14): 4359-4371.

13. Rubin J, Choi Y, Segal R. Cerebellar proteoglycans regulate sonic hedgehog responses during development. Development. 2002;129(9): 2223-2232.

14. Vyas N, Goswami D, Manonmani A, et al. Nanoscale organization of hedgehog is essential for long-range signaling. Cell. 2008;133(7):1214-1217.

15. Wang Y, McMahon A, Allen B. Shifting paradigms in hedgehog signaling. Curr Op Cell Biol. 2007;19(2):159-165.

16. Chuang $\mathrm{P}$, McMahon A. Vertebrate hedgehog signalling modulated by induction of a hedgehog-binding protein. Nature. 1999;397(6720): 617-621.

17. Yao S, Lum L, Beachy P. The Ihog cell-surface proteins bind hedgehog and mediate pathway activation. Cell. 2006;125(2):343-357.

18. McLellan J, Yao S, Zheng X, et al. From the cover: Structure of a heparin-dependent complex of hedgehog and Ihog. Proc Nat Acad Sci US A. 2006;103(46):17208-17213.
19. The I, Bellaiche Y, Perrimon N. Hedgehog movement is regulated through tout velu - dependent synthesis of a heparan sulfate proteoglycan. Mol Cell. 1999;4(4):633-639.

20. Capurro M, Xu P, Shi W, Li F, Jia A, Filmus J. Glypican-3 inhibits hedgehog signaling during development by competing with patched for hedgehog binding. Dev Cell. 2008;14(5):700-711.

21. Chen M, Wilson C, Chuang P. Snapshot: Hedgehog signaling pathway. Cell. 2007;130(2):386.

22. Jacob L, Lum L. Deconstructing the hedgehog pathway in development and disease. Sci Signaling. 2007;318(5847):66-68.

23. Varjosalo M, Taipale J. Hedgehog signaling. J Cell Sci. 2007; 120(1):3-6.

24. Goetz J, Singh S, Suber L, Kull F, Robbins D. A highly conserved aminoterminal region of sonic hedgehog is required for the formation of its freely diffusible multimeric form. J Biol Chem. 2006;281(7):4087-4093.

25. Morales C, Zeng J, El Alfy M, et al. Epithelial trafficking of sonic hedgehog by megalin. J Histochem Cytochem. 2006;54(10):1115-1127.

26. Desbordes S, Sanson B. The glypican Dally-like is required for Hedgehog signalling in the embryonic epidermis of Drosophila. Development. 2003;130(25):6245-6255.

27. Lum L, Yao S, Mozer B, et al. Identification of hedgehog pathway components by RNAi in Drosophila cultured cells. Science. 2003;299(5615): 2039-2045.

28. Beenken A, Mohammadi M. Hedgehogs like it sweet, too. Proc Natl Acad Sci U S A. 2006;103(46):17069-17070.

29. Williams KP, Rayhorn P, Chi-Rosso G, et al. Functional antagonists of sonic hedgehog reveal the importance of the $\mathrm{N}$ terminus for activity. J Cell Sci. 1999;112(Pt 23):4405-4414.

30. Bumcrot D, Takada R, McMahon A. Proteolytic processing yields two secreted forms of sonic hedgehog. Mol Cell Biol. 1995;15(4): 2294-2303.

31. Cardin A, Weintraub H. Molecular modeling of proteinglycosaminoglycan interactions. Arteriosclerosis. 1989;9(1):21-32.

32. Testaz S, Jarov A, Williams K, et al. Sonic hedgehog restricts adhesion and migration of neural crest cells independently of the Patched-Smoothened-Gli signaling pathway. Proc Natl Acad Sci U S A 2001;98(22):12521-12526.

33. Datta M, Hernandez A, Schlicht M, et al. Perlecan, a candidate gene for the CAPB locus, regulates prostate cancer cell growth via the sonic hedgehog pathway. Mol Cancer. 2006;5(1):9.

34. Rubin LL, de Sauvage FJ. Targeting the hedgehog pathway in cancer. Nat Rev Drug Discov. 2006;5(12):1026-1033.

35. Evangelista M, Tian H, de Sauvage FJ. The hedgehog signaling pathway in cancer. Clin Cancer Res. 2006;12(20 Pt 1):5924-5928.

36. Briscoe J, Therond P. Hedgehog signaling: From the Drosophila cuticle to anti-cancer drugs. Dev Cell. 2005;8(2):143-151.

37. Karhadkar S, Bova G, Abdallah N, et al. Hedgehog signalling in prostate regeneration, neoplasia and metastasis. Nature. 2004;431:707-712.

38. Wang L, Liu Z, Gambardella L, et al. Regular articles: Conditional disruption of hedgehog signaling pathway defines its critical role in hair development and regeneration. J Invest Dermatol. 2000;114(5):901-908.

39. Frank-Kamenetsky M, Zhang XM, Bottega S, et al. Small-molecule modulators of Hedgehog signaling: Identification and characterization of Smoothened agonists and antagonists. J Biol. 2002;1(2):10.

40. Chen W, Ren XR, Nelson CD, et al. Activity-dependent internalization of smoothened mediated by beta-arrestin 2 and GRK2. Science. 2004;306(5705):225-260

41. Williams JA, Guicherit OM, Zaharian BI, et al. Identification of a small molecule inhibitor of the hedgehog signaling pathway: Effects on basal cell carcinoma-like lesions. Proc Natl Acad Sci U S A. 2003 ; 100(8):4616-4621.

42. Garber K. Hedgehog drugs begin to show results. J Natl Cancer Inst. 2008;21;100(10):692-697.

43. Mahindroo N, Connelly M, Punchihewa C, et al. Structure activity relationships and cancer-cell selective toxicity of novel inhibitors of glioma-associated oncogene homologue 1 (Gli1) mediated transcription. J Med Chem. 2009;52(14):4277-4287. 
44. Mahindroo N, Punchihewa C, Fujii N. Hedgehog-Gli signaling pathway inhibitors as anticancer agents. J Med Chem. 2009;52(13):3829-3845.

45. Lauth $\mathrm{M}$, Toftgard $\mathrm{R}$. The hedgehog pathway as a drug target in cancer therapy. Curr Opin Investig Drugs. 2007;8(6):457-461.

46. Lauth M, Bergström A, Shimokawa T, Toftgård R. Inhibition of GLI-mediated transcription and tumor cell growth by small-molecule antagonists. Proc Nat Acad Sci U S A . 2007;104(20):8455-8460.

47. Silvian L, Jin P, Carmillo P, et al. Artemin crystal structure reveals insights into heparan sulfate binding. Biochemistry. 2006;45(22): 6801-6812.

48. Zhang F, Fath M, Marks R, Linhardt R. A highly stable covalent conjugated heparin biochip for heparin-protein interaction studies. Anal Biochem. 2002;304(2):271-273.

49. Zhang F, McLellan J, Ayala A, Leahy D, Linhardt R. Kinetic and structural studies on interactions between heparin or heparan sulfate and proteins of the hedgehog signaling pathway. Biochemistry. 2007;46(13):3933-3941.

50. Andrievskaia O, Potetinova Z, Balachandran A, Nielsen K. Binding of bovine prion protein to heparin: A fluorescence polarization study. Arch Biochem Biophys. 2007;460(1):10-16.

51. Aviezer D, Seddon A, Wildey M, Bohlen P, Yayon A. Development of a high throughput screening assay for inhibitors of fibroblast growth factorreceptor-heparin interactions. J Biomol Screen. 2001;6(3):171-177.

52. Huang X, Aulabaugh A. Application of fluorescence polarization in HTS assays. Methods Mol Biol. 2009;565:127-143.

53. Zhang J, Chung T, Oldenburg K. A simple statistical parameter for use in evaluation and validation of high throughput screening assays. J Biomol Screen. 1999;4(2):67-73.

54. Nosjean O, Souchaud S, Deniau C, Geneste O, Cauquil N, Boutin J. A simple theoretical model for fluorescence polarization binding assay development. J Biomol Screen. 2006;11(8):949-958.

55. Ganesh V, Muthuvel S, Smith S, Kotwal G, Murthy K. Structural basis for antagonism by suramin of heparin binding to vaccinia complement protein. Biochemistry. 2005;44(32):10757-10765.
56. Williams K, Scott J. Enzyme assay design for high-throughput screening. Meth Mol Bio. 2009;565:107-126.

57. Ricci L, Williams K. Development of fluorescence polarization assays for the molecular chaperone Hsp70 family members: Hsp72 and DnaK. Curr Chem Genomics. 2008;2(1):90-95.

58. Watkins DN, Berman DM, Burkholder SG, Wang B, Beachy PA, Baylin SB. Hedgehog signalling within airway epithelial progenitors and in small-cell lung cancer. Nature. 2003;422(6929):313-317.

59. Thayer SP, di Magliano MP, Heiser PW, et al. Hedgehog is an early and late mediator of pancreatic cancer tumorigenesis. Nature. 2003;425(6960):851-856.

60. Berman DM, Karhadkar SS, Maitra A, et al. Widespread requirement for hedgehog ligand stimulation in growth of digestive tract tumours. Nature. 2003;425(6960):846-851.

61. Sanchez P, Hernandez AM, Stecca B, et al. Inhibition of prostate cancer proliferation by interference with sonic hedgehog-GLI1 signaling. Proc Natl Acad Sci U S A. 2004;101(34):12561-12566.

62. Lewis M. Hedgehog signaling in mouse mammary gland development and neoplasia. J Mammary Gland Bio Neoplasia. 2001;6(1):53-66.

63. Kubo M, Nakamura M, Tasaki A, et al. Hedgehog signaling pathway is a new therapeutic target for patients with breast cancer. Cancer Res. 2004;64(17):6071-6074.

64. Oniscu A, James RM, Morris RG, Bader S, Malcomson RD, Harrison DJ. Expression of sonic hedgehog pathway genes is altered in colonic neoplasia. J Pathol. 2004;203(4):909-907.

65. Qualtrough D, Buda A, Gaffield W, Williams AC, Paraskeva C. Hedgehog signalling in colorectal tumour cells: Induction of apoptosis with cyclopamine treatment. Int J Cancer. 2004;110(6):831-837.

66. Huang S, He J, Zhang X, et al. Activation of the hedgehog pathway in human hepatocellular carcinomas. Carcinogenesis. 2006;27(7): 1334-1340

67. Stanton B, Peng L, Maloof N, et al. A small molecule that binds hedgehog and blocks its signaling in human cells. Nature Chem Bio. 2009; 5(3):154-156
International Journal of High Throughput Screening

\section{Publish your work in this journal}

International Journal of High Throughput Screening is an international, peer-reviewed, open access journal publishing original research, reports, editorials, reviews and commentaries dedicated to all aspects of high throughput screening, especially related to drug discovery and associated areas of biology and chemistry. The manuscript management sys-

\section{Dovepress}

tem is completely online and includes a very quick and fair peer-review system. Visit http://www.dovepress.com/testimonials.php to read real quotes from published authors. 